Article

\title{
Surface Properties and Structural Transformation Behaviors of mPEG-Maleic Rosin Copolymer in Water
}

\author{
Juying Zhou ${ }^{1,2,3, *}$, Xia Zhang ${ }^{1}$, Yanzhi Zhao ${ }^{1,2}$, Haitang Xu 1,2,3, Pengfei Li 1,2, Hao Li ${ }^{1,2}$, \\ Jinyan Zhang ${ }^{1}$, Qin Huang ${ }^{1,2,3}$ and Fuhou Lei ${ }^{1,2}$ \\ 1 School of Chemistry and Chemical Engineering, Guangxi University for Nationalities, Nanning 530006, \\ China; zx1012574109@126.com (X.Z.); zhaoyzsense@163.com (Y.Z.); xhthellen@163.com (H.X.); \\ lipfgxun@126.com (P.L.); lihaospace@163.com (H.L.); zjy_03@126.com (J.Z.); \\ huangqinpeking@163.com (Q.H.); leifuhou@gxun.cn (F.L.) \\ 2 Guangxi Key Laboratory of Chemistry and Engineering of Forest Products, School of Chemistry and \\ Chemical Engineering, Guangxi University for Nationalities, Nanning 530006, China \\ 3 Key Laboratory of Guangxi Colleges and Universities for Food Safety and Pharmaceutical Analytical \\ Chemistry, School of Chemistry and Chemical Engineering, Guangxi University for Nationalities, \\ Nanning 530006, China \\ * Correspondence: zhoujuying@gxun.edu.cn; Tel.: +86-771-3267019
}

Received: 18 August 2017; Accepted: 15 September 2017; Published: 21 September 2017

\begin{abstract}
PEG (monomethoxy poly(ethylene glycol))-maleic rosin copolymer was successfully prepared. The surface properties of the copolymer were investigated by surface tension and resonance scattering techniques. The critical micelle concentration (CMC) was obtained. The adsorption behaviors and the conformational changes of the surfactant molecules at the air-water interface were described. The adsorption amount of state 1 presented a sinusoid shape and that of state 2 presented a sigmoid with the growth of $\Pi$. The free energy of adsorption is more negative than that of micellization, thus, the surfactant molecules adsorb on the surface firstly, and then form micelles after saturation adsorption. Accordingly, structural transformation and aggregation behaviors of various concentration mPEG-maleic rosin copolymers with changing temperature were explored in water. The mPEG-maleic rosin chains experienced transformation from unimers to aggregates, to contracted aggregates, to cohesive aggregates with increasing temperature when the concentration is lower than CMC. This process is almost reversible with decreasing temperature. Transformation from micelle to aggregate with increasing temperature happened when the concentration is higher than CMC. The phenomena were assessed by DLS (dynamic light scattering) and SEM (scanning electron microscopy) techniques.
\end{abstract}

Keywords: mPEG-maleic rosin copolymer; surface property; structural transformation; aggregation

\section{Introduction}

Water-soluble polymers have attracted a great deal of attention over the years for industrial applications, such as dispersants, stabilizers, emulsifiers, and flocculants [1,2]. The representative synthetic examples include poly(ethylene glycol), poly(vinyl alcohol), poly(meth)acrylate, poly(meth)acrylamide, and poly(vinyl ether). Poly(ethylene glycol) (PEG) is a cheap, neutral, water-soluble, biocompatible, FDA-approved polymer and, thus, poly(ethylene glycol) and its derivatives show potential applications in biotechnology and medicine delivery due to their solubility, nontoxicity, low fouling, and biocompatibility. For example, PEG can be used in precipitating proteins [3], excluding proteins and cells from surfaces [4], reducing immunogenicity and antigenicity [5], and preventing degradation by mammalian cells and enzymes [6]. 
Meanwhile, PEG is a compound which has often been utilized as a conjugated segment to other hydrophobic polymer in copolymer synthesis, and its high hydration capacity is favorable for regulation of the hydrophilicity of the materials. PEG-based thermoresponsive polymers, such as copolymer based on poly(vinyl ether), poly(norbornene), polyester, polystyrene, poly(acrylate), or poly(meth)acrylate have been proposed as interesting alternatives to Poly( $N$-isopropylacrylamide) (PNIPAM) and they display reversible phase transitions as a function of temperature or exhibit defined lower critical solution temperature (LCST) in aqueous or physiological media [7]. The phase transitions were caused by the delicate balance between the hydrophilicity and the hydrophobicity of the polymers [8]. Amphiphilic PEG-based copolymers can also form micelles with hydrophilic PEG as a shell and a hydrophobic segment as the core, which were usually applied in biomedical areas. For example, paclitaxel was covalently connected to monomethoxy-poly(ethylene glycol)- $b$-poly(lactide) and released from the conjugate without losing cytotoxicity [9]. Poly(L-glutamic acid) monomethoxy poly(ethylene glycol) (PLGA-mPEG) copolymer nanoparticles were used as nonocapsules in blood circulation [10]. Zhang et al. synthesized a series of triblock copolymers (polyethylene glycol monomethyl ether)-block-poly(e-caprolactone)-block-poly(2-(dimethylamino) ethyl methacrylate), and investigated the self-assembly behavior of these copolymers, which were used in drug loading and release [11]. In addition to the above-mentioned MPEG copolymers, other copolymers, such as mPEG-chitosan diblock copolymer [12], mPEG-PCL (polycaprolactone) diblock copolymer micelles [13], and mPEG-b-PCL-grafted chitooligosaccharide (COS- $g$-PCL- $b$-mPEG) copolymers [14], have also been produced and successfully used in drug release.

Rosin is a thermoplastic solid resin that occurs naturally in oleoresins of pine trees [15]. Rosin has fair biodegradation and biocompatibility characteristics, as a class of renewable polymerizable monomer, rosin is not soluble in water, but by introducing hydrophilic moieties the rosin-derived polymers become water soluble. For example, non-ionic surfactants based on rosin-imide maleic anhydride adducts were applied as petroleum crude oil sludge dispersants [16]. Tang's group synthesized amphiphilic poly(ethylene glycol) and poly(dehydroabietic ethyl methacrylate) block copolymers, which exhibited superior efficacy in impeding tumor growth [17]. Amphiphilic rosin-based copolymer can undergo conformational transition in water at an optimum balance of hydrophilic and hydrophobic moieties. For instance, in our laboratory, amphiphilic dehydroabietic acid-trimethylolpropane ester and acrylicpimaric acid-PEG ester were synthesized by direct covalent conjugation of dehydroabietic acid and acrylicpimaric acid with trimethylolpropane (TMP) and PEG, respectively, and relevant micellization and structural transformation processes were detected in water $[18,19]$.

In this study, mPEG-maleic rosin copolymer was synthesized. The surface properties, including critical micelle concentration, the minimum surface area of molecules, and the thermodynamic parameters of micellization, have been studied. In the meantime, the structural transformation behavior at the molecular level has also been revealed with the RS technique.

\section{Materials and Methods}

\subsection{Materials}

The mPEG (monomethoxy poly(ethylene glycol))-maleic rosin copolymer was prepared in our laboratory, schematically shown in Figure 1. The mean molecular weight is approximately 3500 and the PDI is 1.32, both were determined by the gel permeation chromatography (GPC) method. Doubly-distilled deionized water was used for all sample preparation and dilution. mPEG-maleic rosin copolymer solution $\left(5 \mathrm{mg} \cdot \mathrm{L}^{-1}\right)$ was prepared by adding a known weight of $\mathrm{mPEG}$-maleic rosin copolymer in water. Different concentrations of $\mathrm{mPEG}$-maleic rosin copolymer aqueous solutions were obtained by dilution. 


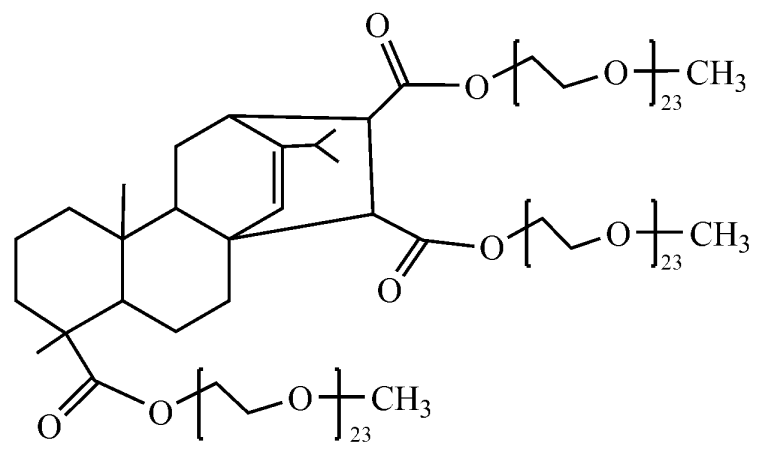

Figure 1. Schematic illustration of mPEG-maleic rosin copolymer.

\subsection{Methods}

The surface tensions of various concentration solutions were measured with a tensiometer BZY-2 (Hengping Instrument Company, Shanghai, China). All solutions of different concentrations were prepared and stored in closed bottles for $24 \mathrm{~h}$ before measurement. The platinum plate was always cleaned and heated to a red/orange color with a Bunsen burner before use. The aging time was at least $20 \mathrm{~min}$.

UV-Vis spectra were measured with a UV-1800 UV-Vis spectrophotometer (Shimadzu, Kyoto, Japan).

Rayleigh light scattering measurements were taken on a LS-55 Fluorescence Spectrophotometer (Perkin Elmer, Waltham, MA, USA) with a xenon lamp. Excitation and emission slits with a bandpass of $2.5 \mathrm{~nm}$ were used for all measurements. The wavelength interval was $0 \mathrm{~nm}$. Temperature-dependence measurements were carried out with the aid of program-controlled closed-cycle water bath equipment, so that the temperature could be maintained with an accuracy of $0.1{ }^{\circ} \mathrm{C}$. The heating rate was $1^{\circ} \mathrm{C} \cdot \mathrm{min}^{-1}$. All the spectra were repeatedly recorded three times to ensure perfect duplication.

Dynamic light scattering (DLS) measurements were performed on a Malvern Instruments Zetasizer Nano ZS (Malvern Instruments Ltd., Southborough, Mass, UK) with a detection angle of $90^{\circ}$. The solutions were filtered through a $0.45 \mu \mathrm{m}$ syringe filter to remove dust particles before measurements. Variable temperature DLS was conducted at the interval of $5{ }^{\circ} \mathrm{C}$. At each temperature the sample was thermally equilibrated for $2 \mathrm{~min}$. The $R_{\mathrm{h}}$ was obtained by the Malvern software (DTS, Malvern Instruments Ltd., Southborough, MA, USA).

Scanning electron microscopy (SEM) was performed to provide structural details of the mPEG-maleic rosin copolymer using a ZEISS SUPRA 55 (Carl Zeiss, Oberkochen, Germany). A small drop of mPEG-maleic rosin copolymer solution was deposited on copper surface at 40,60, 80, and $85{ }^{\circ} \mathrm{C}$, respectively, and dried at the corresponding temperature for at least $48 \mathrm{~h}$. The samples were coated with a very thin layer of platinum before measurements were taken.

\section{Results and Discussion}

\subsection{Equilibrium Surfactant Tension}

The CMC value can be obtained from surface tension measurements of the micellar solutions. As shown in Figure 2, the surface tension decreases slowly at lower concentrations, then a steep descent of surface tension is detected at moderate concentrations, and the surface tension levels off at high concentrations. It is worth noting that the interaction point at $1.5 \mathrm{~g} \cdot \mathrm{L}^{-1}$ of the $\gamma \mathrm{vs}$. $C$ plot is estimated to be the CMC of the MPEG-maleic rosin copolymer. 


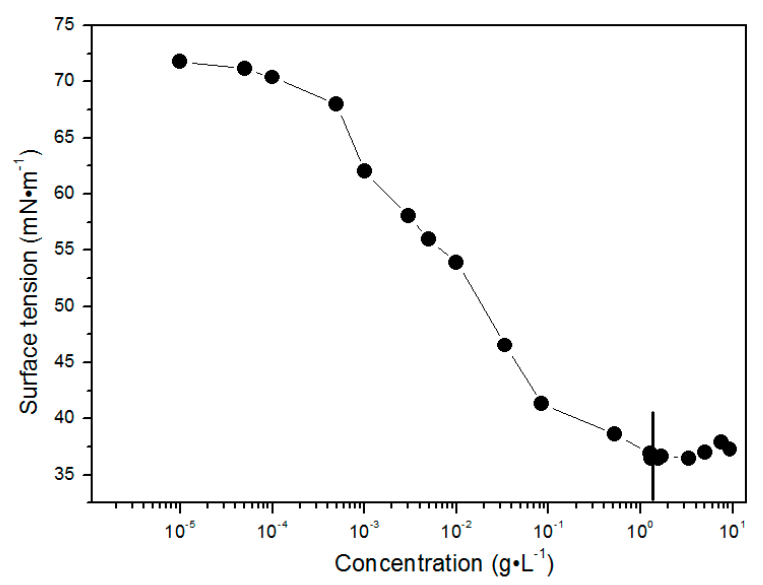

Figure 2. Surface tension changes of mPEG-maleic rosin as a function of concentration.

It can be seen that mPEG-maleic rosin copolymer presents an absorption curve in the UV region, whereas the absorbance approaches almost zero in the range over $300 \mathrm{~nm}$. Thus, the maximum Rayleigh light scattering intensity appears at the red side of the absorption region of the system (about $390 \mathrm{~nm}$ ). Rayleigh light scattering intensity is widely used for the determination of the CMC of micellar systems. The technique is based on significant changes of scattering intensity at the CMC. Figure 3 displays the RS intensity at $390 \mathrm{~nm}$ of mPEG-maleic rosin copolymer solutions with different concentrations, which varied from $0.5 \times 10^{-4}$ to $3 \mathrm{~g} \cdot \mathrm{L}^{-1}$. At lower concentrations, the intensity retains a roughly constant value, then the intensity increases characteristically with concentration, which is attributed to aggregation of mPEG-maleic rosin copolymer chains. Accordingly, the CMC was determined, which is approximately equal to that obtained from the surface tension technique. It is observed that the CMC value of mPEG-maleic rosin copolymer is much higher than that of monomethyl PEG-550 ester of dehydroabietic acid $(0.06 \mathrm{~g} / \mathrm{L})$ and monomethyl PEG-750 ester of dehydroabietic acid $(0.073 \mathrm{~g} / \mathrm{L})$ [20]. This phenomenon is due to more hydrophilic groups and strong hydrophilcity of the mPEG-maleic rosin copolymer.

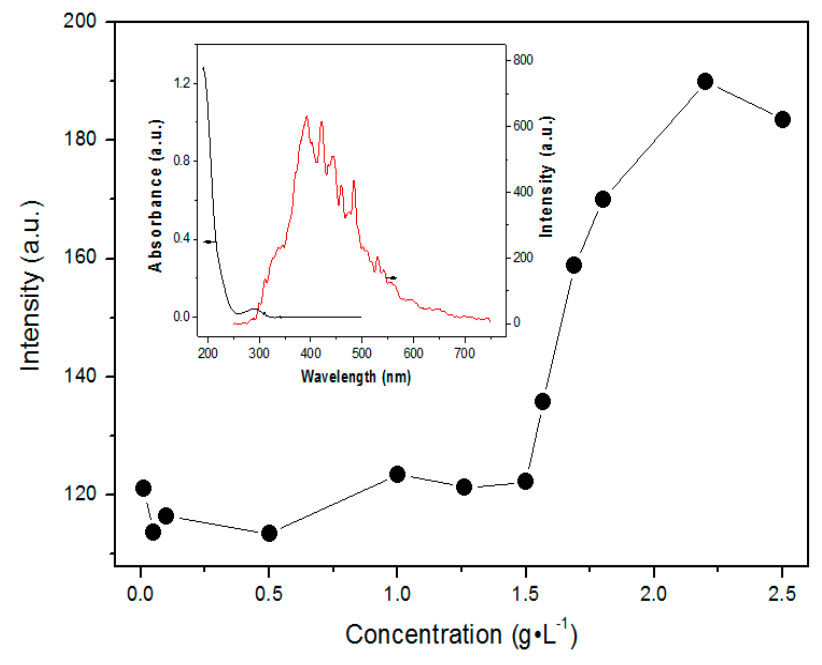

Figure 3. Plot of the Rayleigh scattering intensity at $390 \mathrm{~nm}$ versus concentration of the mPEG-maleic rosin. The inset is the Rayleigh light scattering and absorption spectra of the MPEG-maleic rosin copolymer solution. 


\subsection{Adsorption Behaviors and Conformational Changes of mPEG-Maleic Rosin Copolymer at the Air-Water Interface}

Reorientation theory, which was derived from the Butler equation, provides a reasonable description of the behavior of surfactant molecules at the air-water interface. For simplicity, we assume that there are only two different states in the adsorption layer, 1 and 2, respectively. In state 1 , the majority of adsorbed surfactant molecules present a state with large partial molar surface area $\omega_{1}$ at lower concentration. That is, the adsorption layer consists of molecules only in state 1 when surface pressure is 0 , i.e., $\Pi \approx 0 \mathrm{mN} \cdot \mathrm{m}^{-1}$. On the contrary, the increase of concentration leads to a preferential accumulation of states occupying a minimal molar area of $\omega_{2}$, i.e., state 2 . The adsorption layer consists of molecules only in state 2 when $\Pi>30 \mathrm{mN} \cdot \mathrm{m}^{-1}$.

The adsorption amount in state $1\left(\Gamma_{1}\right)$ can be obtained through the surface tension results and Equation (1), which is derived from the Gibbs-Duhem formula [21]. The adsorption amount in state 2, i.e., $\Gamma_{2}$ can be gained when the concentration is near CMC:

$$
-\frac{d \gamma}{R T}=\Gamma d \ln a
$$

where $\gamma$ is the surface tension, $R$ and $T$ are the gas constant and temperature, respectively, $\Gamma$ is the adsorption amount of surfactant at the air-water interface, and $a$ is the activity of the surfactant in the solution. For dilute solutions, $a$ can be substituted by the surfactant concentration $c$. Therefore, Equation (1) can be specified by:

$$
-\frac{d \gamma}{R T}=\Gamma d \ln c
$$

The partial molar surface area occupied by each adsorbed surfactant molecule can be calculated from $\Gamma$ [22]:

$$
\omega=\frac{1}{N_{A} \Gamma}
$$

$N_{A}$ is the Avogadro constant. Therefore, $\omega_{1}$ is $6.68 \times 10^{6} \mathrm{~m}^{2} \cdot \mathrm{mol}^{-1}$ and the $\omega_{2}$ value is $4.36 \times 10^{5} \mathrm{~m}^{2} \cdot \mathrm{mol}^{-1}$. These results confirm that the molar area become smaller with increasing surface coverage and stronger competition between the adsorbed surfactant molecules, which reflect the adsorption status of mPEG-maleic rosin copolymer molecules [23]. Accordingly, $A_{1}$ and $A_{2}$ are equal to 11.1 and $0.725 \mathrm{~nm}^{2}$, respectively.

The molar fractions of solvent $\chi_{0}$, state $1 \chi_{1}{ }^{\mathrm{s}}$ and state $2 \chi_{2}{ }^{\mathrm{s}}$ change with surfactant concentrations and surface pressures in the surface layer [24].

$$
\begin{gathered}
\gamma_{0}-\gamma=-\frac{R T}{\omega_{0}} \ln \chi_{0}{ }^{\mathrm{S}}=-\frac{R T}{\omega_{0}}\left(1-\chi_{1}{ }^{\mathrm{S}}-\chi_{2}{ }^{\mathrm{S}}\right) \\
\ln \chi_{0}^{\mathrm{s}}=-\frac{\left(\gamma_{0}-\gamma\right) \omega_{0} N_{A}}{R T}
\end{gathered}
$$

The surface area of solvent $\omega_{0}$ can be estimated from the molar area of a bulk-phase $\mathrm{H}_{2} \mathrm{O}$ molecule, e.g., $\omega_{0}=10^{5} \mathrm{~m}^{2} \cdot \mathrm{mol}^{-1}$ [25]. $\chi$ is the molar fraction, subscripts 0,1 , and 2 represent the solvent, state 1 , and state 2 , respectively. The superscript $S$ indicates the surface phase. $\chi_{0}{ }^{\mathrm{s}}, \chi_{1}{ }^{\mathrm{s}}$, and $\chi_{2}{ }^{\mathrm{s}}$ satisfy the following relationship:

$$
\chi_{0}{ }^{\mathrm{s}}+\chi_{1}{ }^{\mathrm{s}}+\chi_{2}{ }^{\mathrm{s}}=1
$$

The molar fractions of solvent $\chi_{0}$, and the sum of $\chi_{1}{ }^{\mathrm{s}}$ and $\chi_{2}{ }^{\mathrm{s}}$ can be obtained.

It can be seen from Figure 4 that $\chi_{0}$ s decreases with increasing $\Pi$, and the sum of molar fractions of state 1 and 2, i.e., $\chi^{\text {s }}$, increases with increasing $\Pi$ due to the increase of the surfactant molecules at the air-water interface. The transformed surface pressure for mPEG-maleic rosin copolymer is approximately $18 \mathrm{mN} \cdot \mathrm{m}^{-1}$. 


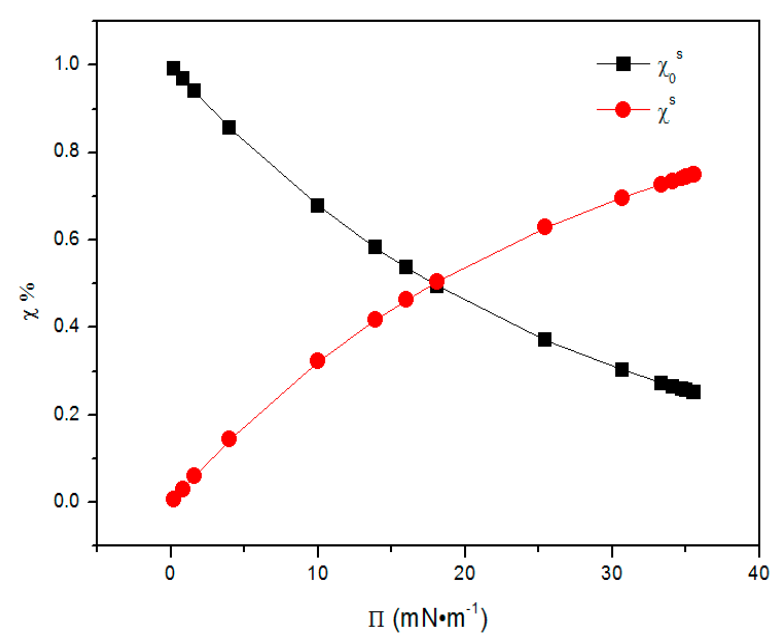

Figure 4. Dependence of the molar fraction of solvent and mPEG-maleic rosin copolymer.

The equation involving the ratio of the adsorption amount in the two possible adsorption states can be deduced from the generalized Joos adsorption equation [26]:

$$
\frac{\Gamma_{1}}{\Gamma_{2}}=\exp \left(\frac{\omega_{1}-\omega_{2}}{\omega}\right)\left(\frac{\omega_{1}}{\omega_{2}}\right)^{\alpha} \exp \left[-\frac{\Pi\left(\omega_{1}-\omega_{2}\right)}{R T}\right]
$$

The total adsorption amount $\Gamma$ and the mean molar area $\omega$ are defined by the following relations:

$$
\begin{gathered}
\Gamma=\Gamma_{1}+\Gamma_{2} \\
\omega \Gamma=\omega_{1} \Gamma_{1}+\omega_{2} \Gamma_{2}
\end{gathered}
$$

It was noted that $\alpha$ is a constant related to the additional surface activity of state 1 . For non-ionic surfactants, $\alpha=0$ [27]. Thus, the $\Pi-\Gamma_{1}$ and $\Pi-\Gamma_{2}$ curves can be obtained. The dependence of the adsorption amounts in states 1 and 2 on surface pressure are shown in Figure 5.

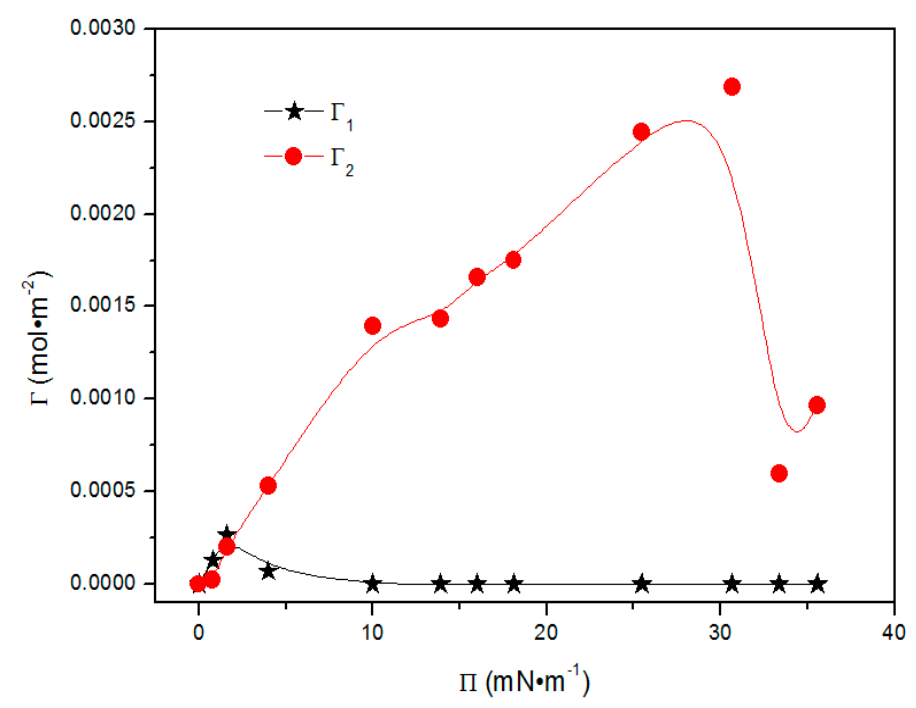

Figure 5. Dependence of the adsorption amount in state 1 and state 2 as a function of surface pressure for $\mathrm{mPEG}$-maleic rosin copolymer. 
Clearly, $\Gamma_{1}$ first increases, and then decreases, with increasing $\Pi$. the $\Gamma_{1}$ curve presents a sinusoid shape, the peak appears at about $1.3 \mathrm{mN} \cdot \mathrm{m}^{-1}$. Meanwhile, it is observed that the $\Gamma_{1}$ value becomes almost constant when $\Pi$ exceeds $10 \mathrm{mN} \cdot \mathrm{m}^{-1}$. The $\Gamma_{2}$ curve nearly presents a sigmoid shape where the $\Gamma_{2}$ increases until $\Pi$ reaches $30 \mathrm{mN} \cdot \mathrm{m}^{-1}$, and $\Gamma_{2}$ decreases when $\Pi$ exceeds $30 \mathrm{mN} \cdot \mathrm{m}^{-1}$. It is also discovered that $\Gamma_{1}$ is larger than $\Gamma_{2}$ when $\Pi$ is below $1.3 \mathrm{mN} \cdot \mathrm{m}^{-1} . \Gamma_{2}$ begins to exceed $\Gamma_{1}$ when $\Pi$ is higher than $1.3 \mathrm{mN} \cdot \mathrm{m}^{-1}$. The variations of $\Gamma_{1}$ and $\Gamma_{2}$ reflect the change of the ratio of molecules in states 1 and 2, showing the evolution of molecular states. It is also found that the adsorption amounts, i.e., both $\Gamma_{1}$ and $\Gamma_{2}$, are much higher than that of oxyethylated surfactants studied by Miller's group [28], which may indicate mPEG-maleic rosin copolymer exhibits better efficiency to reduce surface tension.

\subsection{Free Energies of Adsorption and Micellization}

Surfactant molecules adsorb on the surface, firstly, and then form micelles after saturation adsorption. $\Delta G_{\text {mic }}$ is the molar standard free energy of micellization of surfactants, which is calculated by the equation valid for nonionic surfactants [26]:

$$
\Delta G_{\text {mic }}=R T \ln c_{\mathrm{CMC}}
$$

where the $c_{\mathrm{CMC}}$ is the critical micelle concentration. The molar free energy of adsorption $\Delta G_{\mathrm{ad}}$ is calculated via the following equation:

$$
\Delta G_{\mathrm{ad}}=\Delta G_{\mathrm{mic}}-0.6023 \Pi_{\mathrm{CMC}} A_{\mathrm{min}}
$$

where $A_{\text {min }}=A_{\mathrm{CMC}}=\omega_{2}$. Thus, $\Delta G_{\text {mic }}$ of mPEG-maleic rosin copolymer is equal to $-24.406 \mathrm{~kJ} \cdot \mathrm{mol}^{-1}$ indicating that the micellization process is spontaneous. $\Delta G_{\text {ad }}$ is $-40.31 \mathrm{~kJ} \cdot \mathrm{mol}^{-1}$, the value is more negative than $\Delta G_{\text {mic }}$, demonstrating that the adsorption at the surface is associated with a decrease in the free energy of the system. The result may be due to the steric effect of the phenanthrene ring on the inhibition of micellization more than on adsorption.

\subsection{Structural Transformation and Aggregation Behaviors of mPEG-Maleic Rosin Copolymer in Water}

Here, the structure transformation processes of mPEG-maleic rosin copolymer solutions below and above $\mathrm{CMC}$ with changing temperature were detected. Figure 6 depicts the temperature dependence of the scattering intensity at $390 \mathrm{~nm}$ for $0.13 \mathrm{~g} \cdot \mathrm{L}^{-1} \mathrm{mPEG}$-maleic rosin copolymer in the temperature range of $25-95{ }^{\circ} \mathrm{C}$. It is worth noting that the inflection points on the curve are associated with different stages of structural transformations upon heating. These stages roughly include structural transformation and aggregation accompanied with the size change of the scatterers. mPEG-maleic rosin copolymer chains exist as individual unimers in water at $25^{\circ} \mathrm{C}$ due to the fact that the concentration is lower than CMC. As shown in Figure 6, the first stage is in the temperature region from 25 to $38^{\circ} \mathrm{C}$. In this stage Rayleigh scattering intensity increases rapidly and individual unimers aggregate together with increasing temperature. Here, the aggregations are composed of a hydrophobic core with a maleic rosin segment, carrying hydrophilic mPEG segments in the periphery to ensure solubility. The reason for this phenomenon is that the hydrophobic interactions between maleic rosin moieties increase with increasing temperature. As the temperature is raised further, the scattering intensity decreases in the temperature range from $38-81^{\circ} \mathrm{C}$. The reduction in intensity suggests that the size of the aggregations formed in the previous stage begins to decrease. Owing to relaxation of local mPEG molecular chain segments, the aggregation dimension shrinks and a reduction in the scattering intensity is observed. It is worth noting that in this temperature range the hydrogen bonds between mPEG chains and water begin to break and dehydration takes place with increasing temperature and balance between hydrophilicity and hydrophobicity is once again established, leading to contracted aggregates dispersing in water stably. An enhancement in the scattering intensity is observed again when temperature exceeds $81^{\circ} \mathrm{C}$. This phenomenon is probably attributed to the LCST behavior of 
mPEG chains in water [29]. Here, further inter-cohesion of contracted aggregates were obtained, which results from the sustained disruption of the hydrogen bonding network between ether oxygen groups and water molecules. The Rayleigh scattering intensity variation for $0.13 \mathrm{~g} \cdot \mathrm{L}^{-1} \mathrm{mPEG}$-maleic rosin solution was collected during the cooling process, the results are also shown in Figure 6. It can be seen that the intensity presents a decrease at the initial stage of cooling, which is in the temperature range of $95-81{ }^{\circ} \mathrm{C}$. Here, the aggregation size reduced. From $81^{\circ} \mathrm{C}$ to $43{ }^{\circ} \mathrm{C}$, the intensity increased slowly, indicating that the scatterers' size increased. Then the intensity decreases when the temperature is lower than $43^{\circ} \mathrm{C}$. Clearly, in this temperature range, the scattering intensity variation mainly comes from the inverse transformation process from inter-cohesion aggregates, to shrunk aggregates, to aggregates during cooling. It is worth noting that the transformation temperature from aggregates to unimers in the cooling process is $43^{\circ} \mathrm{C}$, which is higher than that in the heating process, thus, the structural transformation behavior does not overlap completely. Here, the irreversible result may be due to the faster stretch of chains and the formation of hydrogen bonds in concentrated solution with decreasing temperature. The reason for the lower intensity scattering intensity after a heating and cooling cycle is that the cooling rate is rapid and the transformation rate cannot keep up with the cooling process [30].

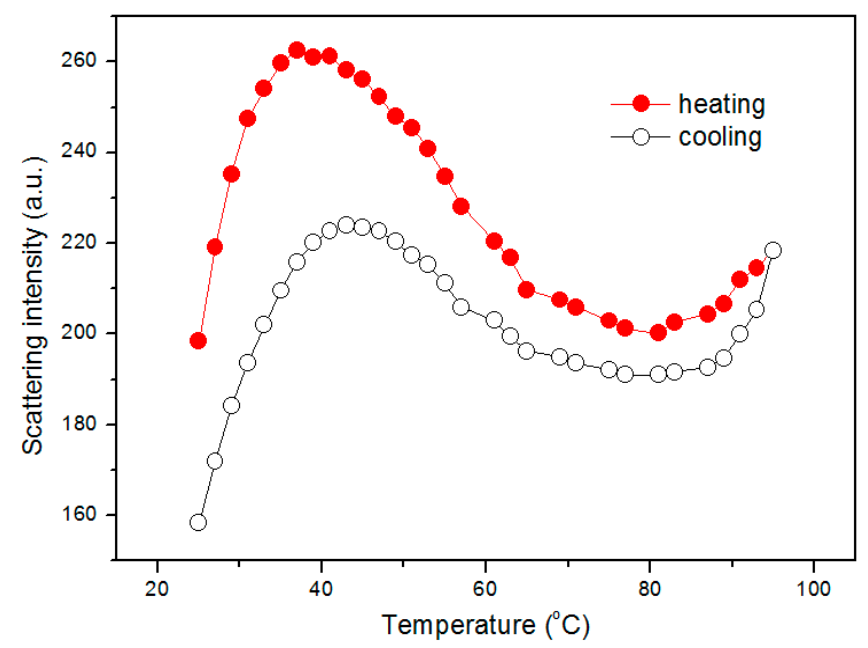

Figure 6. Scattering intensity of $0.13 \mathrm{~g} \cdot \mathrm{L}^{-1} \mathrm{mPEG}$-maleic rosin solution at $390 \mathrm{~nm}$ as a function of temperature during heating and cooling process.

In order to gain more detailed information about the structural transformation of mPEG-maleic rosin copolymer chains in water, Rayleigh scattering intensity variation for 0.6 and $1 \mathrm{~g} \cdot \mathrm{L}^{-1} \mathrm{mPEG}$-maleic rosin copolymer solutions were collected during heating, the results are shown in Figure 7a,b, respectively. It is worth noting that similar results were found in these two solutions. It is observed that the transition temperature from aggregation to contracted aggregates is about $65^{\circ} \mathrm{C}$ and $55^{\circ} \mathrm{C}$, respectively. The stability of such a copolymer would be a weighted average of these hydrogen bond and hydrophobic contributions. Hydrophobic effects and hydrogen bonding make comparable contributions to the stability of the copolymer at room temperature. It is well known that the formation of the hydrophobic bond is endothermic at low temperature and the strength of the hydrophobic bond increases with increasing temperature. Hydrogen bonds have a temperature dependence opposing hydrophobic bonds. Thus, the irregularity of the transition temperature may come from a different extent of contact between maleic rosin moieties, competition, and predomination of these two kinds of interaction in governing the temperature dependence of stability [31]. However, the transition temperatures from contracted aggregates to inter cohesion of aggregates are almost the same, i.e., $82{ }^{\circ} \mathrm{C}$ and $80^{\circ} \mathrm{C}$, respectively, which is almost the same with the results mentioned above. Meanwhile, the Rayleigh scattering intensity variations of 0.6 and $1 \mathrm{~g} \cdot \mathrm{L}^{-1}$ solutions were collected during the cooling 
process. A close observation of $0.6 \mathrm{~g} \cdot \mathrm{L}^{-1} \mathrm{mPEG}$-maleic rosin solution indicates that, in the cooling process, scattering intensity decreases firstly, then the scattering intensity begins to increase at about $75{ }^{\circ} \mathrm{C}$, and finally the scattering intensity decreases again when the temperature is lower than $60^{\circ} \mathrm{C}$. Similar results can be obtained in the $1 \mathrm{~g} \cdot \mathrm{L}^{-1} \mathrm{mPEG}$-maleic rosin copolymer solution, as shown in Figure $7 \mathrm{~b}$. The transformation temperatures from inter-cohesion aggregates to shrunk aggregates almost identify with those in the heating process. The transformation temperature from shrunk aggregates to aggregates for $0.6 \mathrm{~g} \cdot \mathrm{L}^{-1}$ is equal to that in the heating process. However, the transformation temperature for $1 \mathrm{~g} \cdot \mathrm{L}^{-1}$ is $64{ }^{\circ} \mathrm{C}$, higher than $55^{\circ} \mathrm{C}$ in the heating process. This phenomenon is identified with the results from $0.13 \mathrm{~g} \cdot \mathrm{L}^{-1} \mathrm{mPEG}-\mathrm{maleic}$ rosin copolymer solutions.
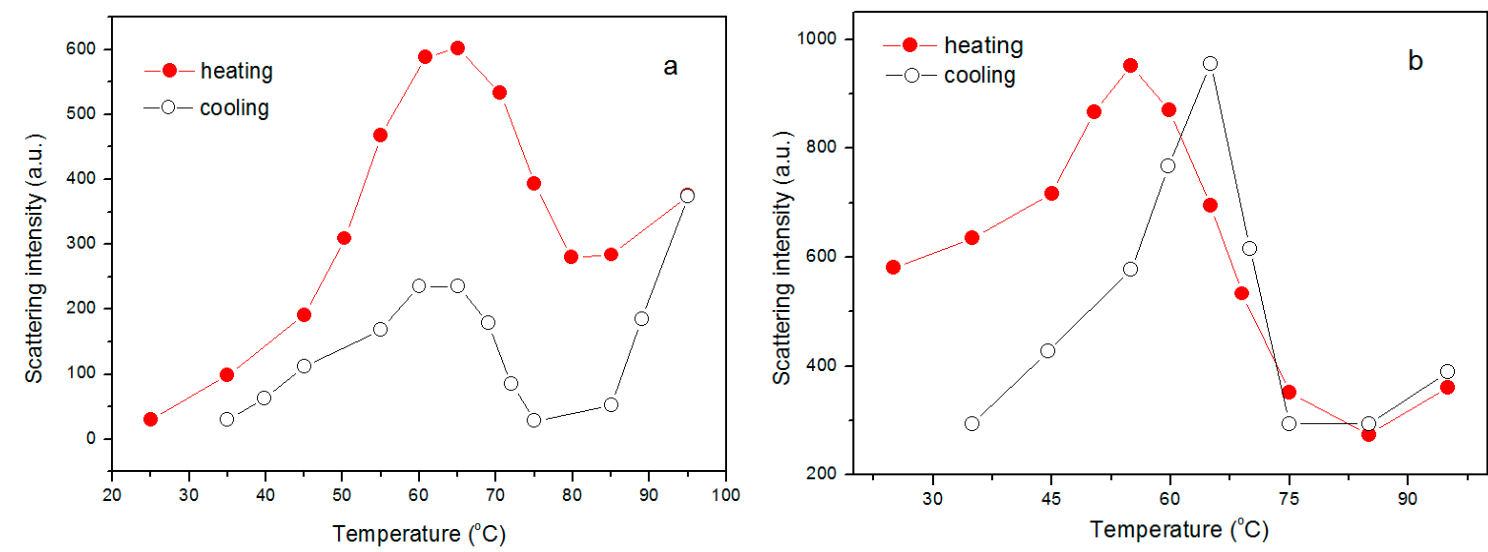

Figure 7. Scattering intensity of 0.6 and $1 \mathrm{~g} \cdot \mathrm{L}^{-1} \mathrm{mPEG}$-maleic rosin solutions at $390 \mathrm{~nm}$ as a function of temperature during one heating and cooling cycle: (a) $0.6 \mathrm{~g} \cdot \mathrm{L}^{-1}$; and (b) $1 \mathrm{~g} \cdot \mathrm{L}^{-1}$.

Temperature dependence of $\mathrm{I}_{390}$ for $1.62 \mathrm{~g} \cdot \mathrm{L}^{-1}$ of mPEG-maleic rosin copolymer solution (above $\mathrm{CMC}$ ) during one heating and cooling cycle is plotted in Figure 8. It can be observed that, in the heating process, the scattering intensity remains constant below $45^{\circ} \mathrm{C}$ and increases rapidly when the temperature is above $45^{\circ} \mathrm{C}$. In the initial constant period, the micelle is in the equilibrium phase and is stabilized in water, creating no intensity fluctuation due to the moderate repulsive force between hydrophilic groups. The following increase of scattering intensity means further aggregation of micelles, which is assigned to the dehydration of hydrophilic mPEG chains on the peripheral shell. In the following cooling process, the descending of the intensity is almost identical with the heating curve.

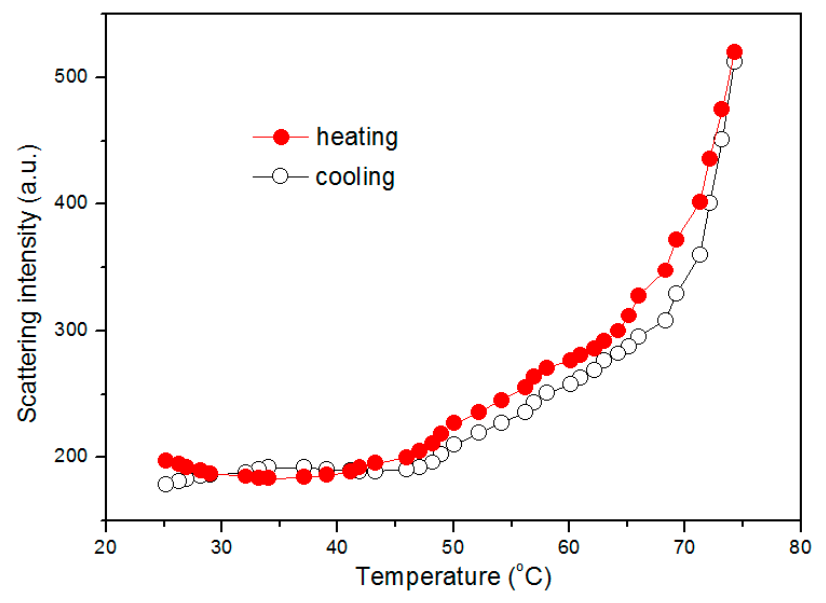

Figure 8. Temperature dependence of $\mathrm{I}_{390}$ for $1.62 \mathrm{~g} \cdot \mathrm{L}^{-1} \mathrm{mPEG}$-maleic rosin solution during one heating and cooling cycle. 
To obtain direct evidence of structural transformation and aggregation behaviors, the typical microscopic morphologies of $0.6 \mathrm{~g} \cdot \mathrm{L}^{-1} \mathrm{mPEG}$-maleic rosin aqueous solution deposited at 40, 60, 80, and $85{ }^{\circ} \mathrm{C}$ are provided in Figure 9. It was found that at $40{ }^{\circ} \mathrm{C}$, worm-shaped individual unimers are presented in Figure 9a. A close observation exhibit that there are also some aggregates in this temperature which may indicates that unimers aggregate together in drying. As the temperature increases to $60{ }^{\circ} \mathrm{C}$, the unimers form large aggregates with an average diameter in the range of 200-250 $\mathrm{nm}$ (Figure 9b). Spherical aggregates with a diameter of about $50-80 \mathrm{~nm}$ appear at $80{ }^{\circ} \mathrm{C}$ (Figure 9c), the results mean that the aggregates formed at $60^{\circ} \mathrm{C}$ are deformed by heating. Gear-shaped aggregates with a diameter of about $100 \mathrm{~nm}$ appear at $85{ }^{\circ} \mathrm{C}$ (Figure $9 \mathrm{~d}$ ), which may due to the gathering of spherical aggregates.

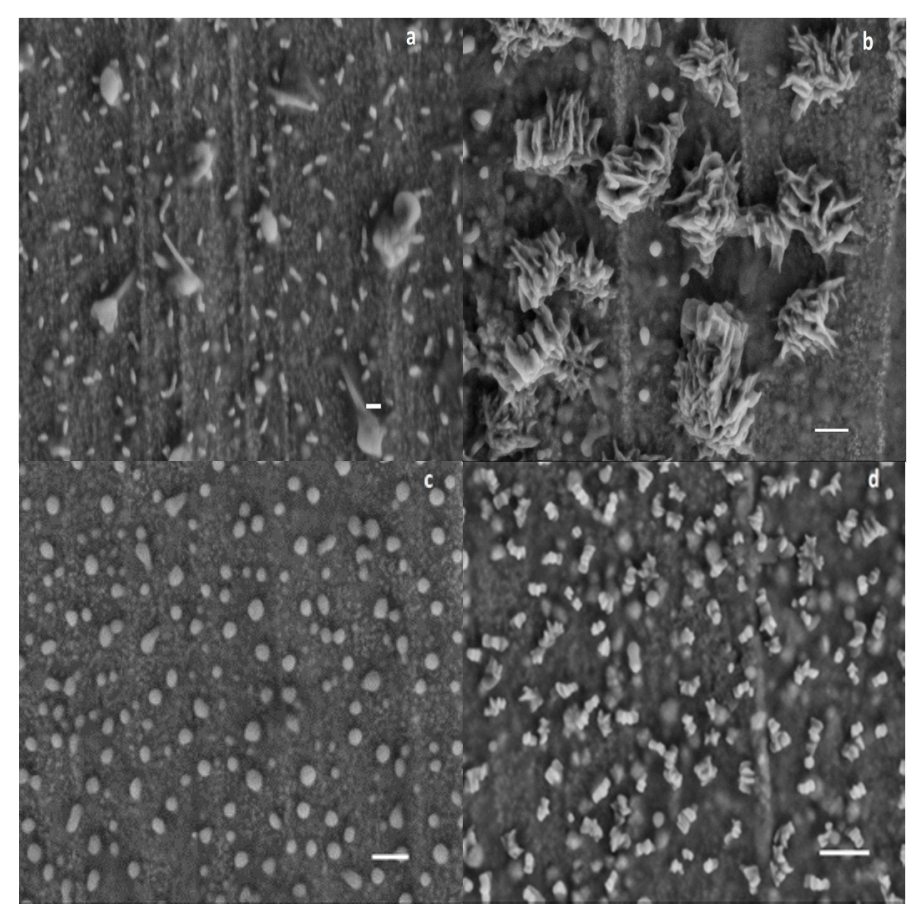

Figure 9. SEM images of the $\mathrm{mPEG}$-maleic rosin aggregates at various temperatures. The deposited temperatures include: (a) $40{ }^{\circ} \mathrm{C}$; (b) $60^{\circ} \mathrm{C}$; (c) $80^{\circ} \mathrm{C}$; and (d) $85^{\circ} \mathrm{C}$. Scale bars: (a) $100 \mathrm{~nm}$; (b,c) $200 \mathrm{~nm}$; and (d) $300 \mathrm{~nm}$.

In the meantime, the DLS measurements were performed to study the size variation as a structure transformation. Figure 10 displays the temperature dependence of $R_{\mathrm{h}}$ of $0.6 \mathrm{~g} \cdot \mathrm{L}^{-1} \mathrm{mPEG}-\mathrm{maleic}$ rosin in water. It can be seen that the $R_{\mathrm{h}}$ is approximately $100 \mathrm{~nm}$ at $25^{\circ} \mathrm{C}$. The $R_{\mathrm{h}}$ then gradually increases when the temperature increases, indicating the aggregation of unimers and then $R_{\mathrm{h}}$ reaches a maximum of about $270 \mathrm{~nm}$ at about $60^{\circ} \mathrm{C}$, it decreases to $50 \mathrm{~nm}$ at $75^{\circ} \mathrm{C}$, and then it increases again above $80^{\circ} \mathrm{C}$. In the cooling process $R_{\mathrm{h}}$ gradually decreases with temperature and then $R_{\mathrm{h}}$ begins to increase, reaching a maximum at about $67^{\circ} \mathrm{C}$, and decreases in the temperature range of $67-25^{\circ} \mathrm{C}$. These results demonstrate that the $R_{\mathrm{h}}$ obtained by the DLS method is almost consistent with the results observed by Rayleigh scattering and SEM techniques. The difference of $R_{\mathrm{h}}$ from DLS and SEM comes from the different testing methods.

According to the above analysis, the structural transformation and aggregation of mPEG-maleic rosin chains during one heating and cooling cycle can be simply described as follows: an almost reversible aggregation of unimers occurred at low temperature, and the aggregation process is followed by another reversible transformation process from the larger aggregates to spherical aggregates and to gear aggregates with increasing temperature. A model is proposed to depict the entire 
structural transformation and aggregation of mPEG-maleic rosin chains during the heating and cooling processes in Figure 11. The morphologies are similar to those of "crew-cut" micelle-like aggregates of polystyrene- $b$-poly(acrylic acid) copolymers in aqueous solutions $[32,33]$. The thermo-induced multi morphologies transformation of mPEG-maleic rosin chains make it potentially useful as a carrier due to similar characteristics with block copolypeptoids in water $[34,35]$.

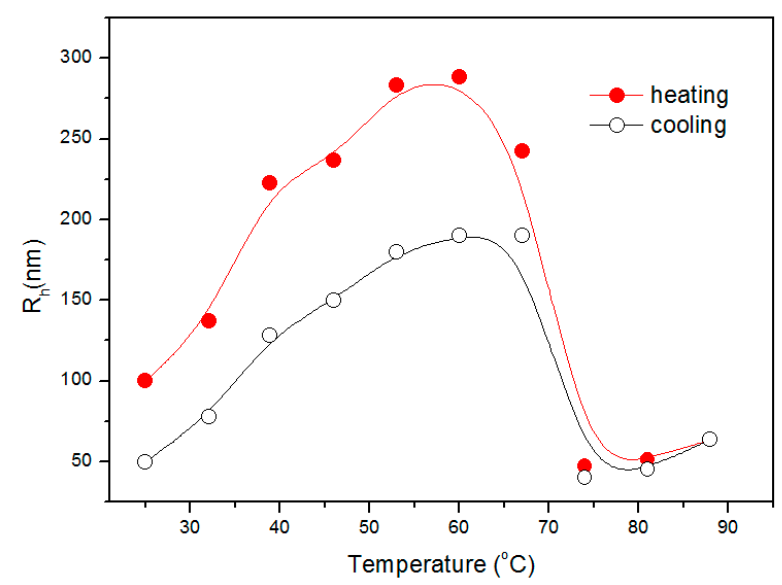

Figure 10. Temperature dependence of $R_{\mathrm{h}}$ for $0.6 \mathrm{~g} \cdot \mathrm{L}^{-1} \mathrm{mPEG}-\mathrm{maleic}$ rosin solution collected during one heating and cooling cycle.

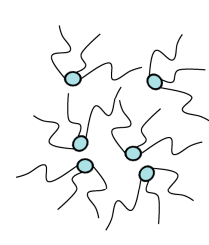

Unimers

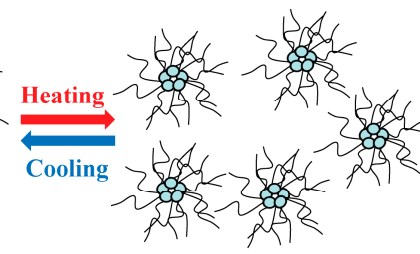

Aggregates

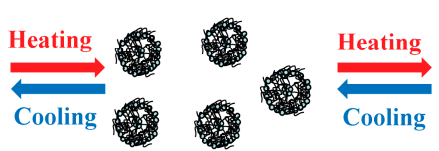

Spherical aggregates

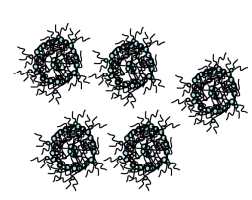

Gear aggregates

maleic rosin segment

mPEG chains

Figure 11. Evolution of structural transformation and aggregation of mPEG-maleic rosin chains during heating and cooling processes.

\section{Conclusions}

In conclusion, the CMC value of mPEG-maleic rosin was decided by surface tension and scattering techniques. Reorientation theory was proposed to describe the adsorption states, adsorption behaviors, and adsorption processes of mPEG-maleic rosin at the air-water interface. The mPEG-maleic rosin adsorbed on the air-water interface in two different states; they are state 1 and state 2 . The molar fraction of solvent decreased, and the sum of molar fractions of these two states increased, with the increasing surface pressure. The adsorption amounts of state 1 presented a sinusoid shape and those of state 2 presented a sigmoid shape with the growth of $\Pi$. Free energies of adsorption are more negative than micellization, which demonstrated the surfactant molecules adsorbing on the surface, firstly, and then forming micelles after saturation adsorption. The structural transformations of mPEG-maleic rosin chains were investigated by RS, SEM, and DLS techniques. Structural transformation from unimers, to aggregates, to spherical aggregates, to gear aggregates with increasing temperature was monitored when the concentration is lower than $\mathrm{CMC}$, which is almost a reversible process during cooling process. Transformation from micelle to aggregate with increasing temperature happened when the concentration was higher than CMC. 
Acknowledgments: This work was supported by the National Natural and Science Foundation of China (21606056, 31700505) and the Scientific Research Fund of Guangxi Education Department (grant No. KY2015YB080). The authors also acknowledge the Xiangsihu Young Scholars Innovative Research Team of Guangxi University for Nationalities.

Author Contributions: Xia Zhang, Yanzhi Zhao, and Hao Li Prepared the mPEG-maleic rosin copolymer. Pengfei Li, Qin Huang, and Haitang Xu measured the data, including the preparation of the solution samples. Juying Zhou, Jinyan Zhang, and Fuhou Lei participated in the data processing. All authors participated in writing the paper.

Conflicts of Interest: The authors declare no conflict of interest.

\section{References}

1. Wesslén, B.; Wesslén, K.B. Preparation and properties of some water-soluble, comb-shaped, amphiphilic polymers. J. Polym. Sci. Polym. Chem. 1989, 27, 3915-3926. [CrossRef]

2. Han, S.; Hagiwara, M.; Ishizone, T. Synthesis of thermally sensitive water-soluble polymethacrylates by living anionic polymerizations of oligo(ethylene glycol) methyl ether methacrylates. Macromolecules 2003, 36, 8312-8319. [CrossRef]

3. Poison, A. A theory for the displacement of proteins and viruses with polyethylene glycol. Prep. Biochem. 1977, 7, 129-154. [CrossRef] [PubMed]

4. Gombotz, W.R.; Guanghui, W.; Horbett, T.; Hoffman, A.S. Protein adsorption to and elution from polyether surfaces. In Polyethylene Glycol Chemistry: Biotechnical and Biomedical Applications, 1st ed.; Harris, J.M., Zalipsky, S., Eds.; Springer: Washington, DC, USA, 1992; Volume 16, pp. 247-261.

5. Working, P.K.; Newman, M.S.; Johnson, J.; Cornacoff, J.B. Safety of poly(ethylene glycol) and poly(ethylene glycol) derivatives. In Poly(ethyleneglycol) Chemistry and Biological Applications, 2nd ed.; Harris, J.M., Zalipsky, S., Eds.; ACS Symposium: Washington, DC, USA, 1997; Volume 4, pp. 45-57.

6. Richter, A.W.; Akerblom, E. Antibodies against polyethyleneglycolproduced in animals by immunizaion with monomethoxy polyethylene glycol modified proteins. Int. Arch. Allergy Appl. Immunol. 1983, 70, 124-131. [CrossRef] [PubMed]

7. Kesse, S.; Schmidt, S.; Múller, R.; Wischerhoff, E.; Laschewsky, A.; Lutz, J.F.; Fery, A. Thermoresponsive PEG-based polymer layers: Surface characterization with AFM force measurements. Langmuir 2009, 26, 3462-3467. [CrossRef] [PubMed]

8. Luzon, M.; Boyer, C.; Peinado, C.; Corrales, T.; Whittaker, M.; Tao, L.; Davis, T.P. Water-soluble, thermoresponsive, hyperbranched copolymers based on PEG-methacrylates: Synthesis, characterization, and LCST behavior. J. Polym. Sci. Polym. Chem. 2010, 48, 2783-2792. [CrossRef]

9. Zhang, X.; Li, Y.; Chen, X.; Wang, X.; Xu, X.; Liang, Q.; Jing, X. Synthesis and characterization of the paclitaxel/mPEG-PLA block copolymer conjugate. Biomaterials 2005, 26, 2121-2128. [CrossRef] [PubMed]

10. Avgoustakis, K.; Beletsi, A.; Panagi, Z.; Klepetsanis, P.; Livaniou, E.; Evangelatos, G.; Ithakissios, D.S. Effect of copolymer composition on the physicochemical characteristics, in vitro stability, and biodistribution of PLGA-PEG nanoparticles. Int. J. Pharm. 2003, 259, 115-127. [CrossRef]

11. Zhang, W.; He, J.; Liu, Z.; Ni, P.; Zhu, X. Biocompatible and pH-responsive triblock copolymer mPEG-b-PCL- $b$-PDMAEMA: Synthesis, self-assembly, and application. J. Polym. Sci. Polym. Chem. 2010, 48, 1079-1091. [CrossRef]

12. Kong, X.; Li, X.; Wang, X.; Liu, T.; Gu, Y.; Guo, G.; Qian, Z. Synthesis and characterization of a novel mPEG-chitosan diblock copolymer and self-assembly of nanoparticles. Carbohydr. Polym. 2010, 79, 170-175. [CrossRef]

13. Gou, M.; Zheng, X.; Men, K.; Zhang, J.; Wang, B.; Lv, L.; Zhao, X. Self-assembled hydrophobic honokiol loaded mPEG-PCL diblock copolymer micelles. Pharm. Res. 2009, 26, 2164-2173. [CrossRef] [PubMed]

14. Zhao, S.; Lee, J.; Xu, W. Supramolecular hydrogels formed from biodegradable ternary COS- $g$-PCL- $b$-mPEG copolymer with $\alpha$-cyclodextrin and their drug release. Carbohydr. Res. 2009, 344, 2201-2208. [CrossRef] [PubMed]

15. Morkhade, D.M.; Nande, V.S.; Barabde, U.V.; Patil, A.T.; Joshi, S.B. PEGylated rosin derivatives: Novel microencapsulating materials for sustained drug delivery. AAPS PharmSciTech 2007, 8, E134-E142. [CrossRef] [PubMed] 
16. Atta, A.M.; Elsaeed, A.M. Use of rosin-based nonionic surfactants as petroleum crude oil sludge dispersants. J. Appl. Polym. Sci. 2011, 122, 183-192. [CrossRef]

17. Wang, J.; Yao, K.; Wang, C.; Tang, C.; Jiang, X. Synthesis and drug delivery of novel amphiphilic block copolymers containing hydrophobic dehydroabietic moiety. J. Mater. Chem. B 2013, 1, 2324-2332. [CrossRef]

18. Zhou, J.; Yang, Y.; Liang, Y.; Lei, F.; Xu, H.; Lu, J.; Zhou, Y. Adsorption Behavior of TrimethylolpropaneDehydroabietic Acid Ester at the Air-water Interface. J. Surfactants Deterg. 2016, 19, 1143-1151. [CrossRef]

19. Zhao, Y.; Zhou, J.; Lei, F.; Xu, H.; Lu, J.; Huang, Z.; Li, P. Temperature induced multiple structure transformation and aggregation behaviors of amphiphilic acrylicpimaric acid polyglycol ester in water. Polymer 2017, 118, 49-57. [CrossRef]

20. Piispanena, P.S.; Mikael Kjellinb, U.R.; Hedmana, B.; Norina, T. Synthesis and Surface Measurements of Surfactants Derived from Dehydroabietic Acid. J. Surfactants Deterg. 2003, 6, 125-130. [CrossRef]

21. Huang, Z.Y.; Zhang, T.L.; Lu, H.C. Surface and Colloid Chemistry; Petroleum Chemical Press: Beijing, China, 2012.

22. Makievski, A.V.; Fainerman, V.B.; Bree, M.; Wustneck, R.; Kralgel, J.; Miller, R. Adsorption of proteins at the liquid/air interface. J. Phys. Chem. B 1998, 102, 417-425. [CrossRef]

23. Miller, R.; Fainerman, V.B.; Makievski, A.V.; Kragel, J.; Grigoriev, D.O.; Kazakov, V.N.; Sinyachenko, O.V. Dynamics of protein and mixed protein/surfactant adsorption layers at the water/fluid interface. Adv. Colloid Interface Sci. 2000, 86, 39-82. [CrossRef]

24. Fainerman, V.B.; Miller, R.; Wüstneck, R.; Makievski, A.V. Adsorption isotherm and surface tension equation for a surfactant with changing partial molar area. 1. Ideal surface layer. J. Phys. Chem. 1996, 100, 7669-7675. [CrossRef]

25. Fainerman, V.B.; Zholob, S.A.; Lucassen-Reynders, E.H.; Miller, R. Comparison of various models describing the adsorption of surfactant molecules capable of interfacial reorientation. J. Colloid Interface Sci. 2003, 261, 180-183. [CrossRef]

26. Rosen, M.J.; Kunjappu, J.T. Surfactants and Interfacial Phenomena, 4th ed.; John Wiley \& Sons: Hoboken, NJ, USA, 2012; pp. 39-122, 9780470541944.

27. Fainerman, V.B.; Lucassen-Reynders, E.H.; Miller, R. Adsorption of surfactants and proteins at fluid interfaces. Colloid Surf. A Physicochem. Eng. Asp. 1998, 143, 141-165. [CrossRef]

28. Miller, R.; Fainerman, V.B.; Möhwald, H. Adsorption behavior of oxyethylated surfactants at the air/water interface. J. Colloid Interface Sci. 2002, 247, 193-199. [CrossRef] [PubMed]

29. Tager, A.A.; Vshivkov, S.A.; Andreyeva, V.M.; Sekacheva, T.V. The structure of polyoxyethylene solutions with lower critical temperatures of mixing. Polym. Sci. U.S.S.R. 1974, 16, 7-14. [CrossRef]

30. Zhou, J.; Yang, J.; Hu, C.; Yang, K.; Zhang, B.; Chen, X. Structure evolution and kinetics steps of the melting process of thermoreversible polymer gels. Soft Matter 2011, 7, 5010-5019. [CrossRef]

31. Scheraga, H.A.; Némethy, G.; Steinberg, I.Z. The contribution of hydrophobic bonds to the thermal stability of protein conformations. J. Biol. Chem. 1962, 237, 2506-2508. [PubMed]

32. Zhang, L.F.; Eisenberg, A. Multiple Morphologies of "Crew-Cut" Aggregates of Polystyrene- $b$-poly(acrylic acid) Block Copolymers. Science 1995, 268, 1728-1731. [CrossRef] [PubMed]

33. Zhang, L.F.; Eisenberg, A. Multiple Morphologies and Characteristics of "Crew-Cut" Micelle-like Aggregates of Polystyrene- $b$-poly(acrylic acid) Diblock Copolymers in Aqueous Solutions. J. Am. Chem. Soc. 1996, 118, 3168-3181. [CrossRef]

34. Secker, C.; Volkel, A.; Tiersch, B.; Koetz, J.; Schlaad, H. Thermo-Induced Aggregation and Crystallization of Block Copolypeptoids in Water. Macromolecules 2016, 49, 979-985. [CrossRef]

35. Bogomolova1, A.; Secker, C.; Koetz, J.; Schlaad, H. Thermo-induced multistep assembly of double-hydrophilic block copolypeptoids in water. Colloid Polym. Sci. 2017, 295, 1305-1312. [CrossRef]

(C) 2017 by the authors. Licensee MDPI, Basel, Switzerland. This article is an open access article distributed under the terms and conditions of the Creative Commons Attribution (CC BY) license (http://creativecommons.org/licenses/by/4.0/). 